\section{Cycles in Social Behaviour}

Young and Ziman, writing about Cycles in Social Behaviour ${ }^{1}$, suggest that "cycles of personal behaviour . . . are partly governed by endogenous biological mechanisms which need to be sustained by food and sleep at more or less regular intervals".

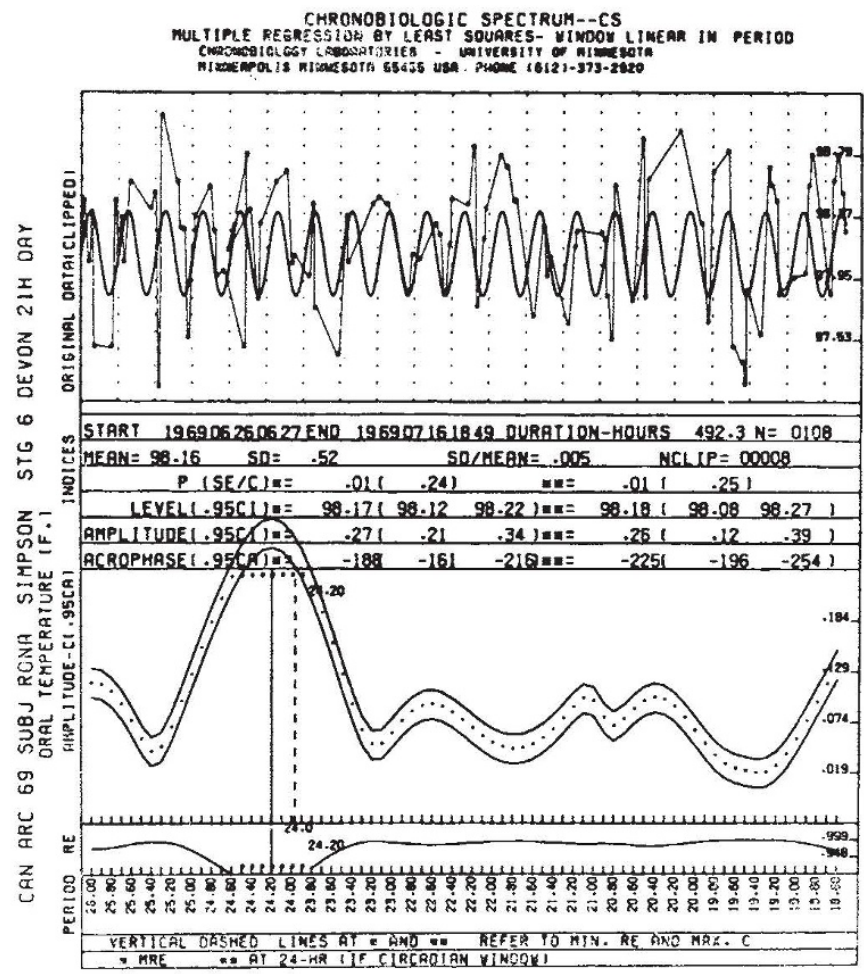

Fig. 11969 Canadian Arctic $21 \mathrm{~h}$ day survey in Devon Island. Oral temperature of one subject (Rona Simpson) aged 7. At top, 3 weeks raw data in ${ }^{\circ} \mathrm{F}$ with overprint of best fit cosine wave in spectrum $26.0 \mathrm{~h}$ to $18.6 \mathrm{~h}$ with $0.2 \mathrm{~h}$ interval. At bottom, serial amplitudes with the 0.95 confidence limits. Also residual error (r.e.) the minimum of which indicates best fit.

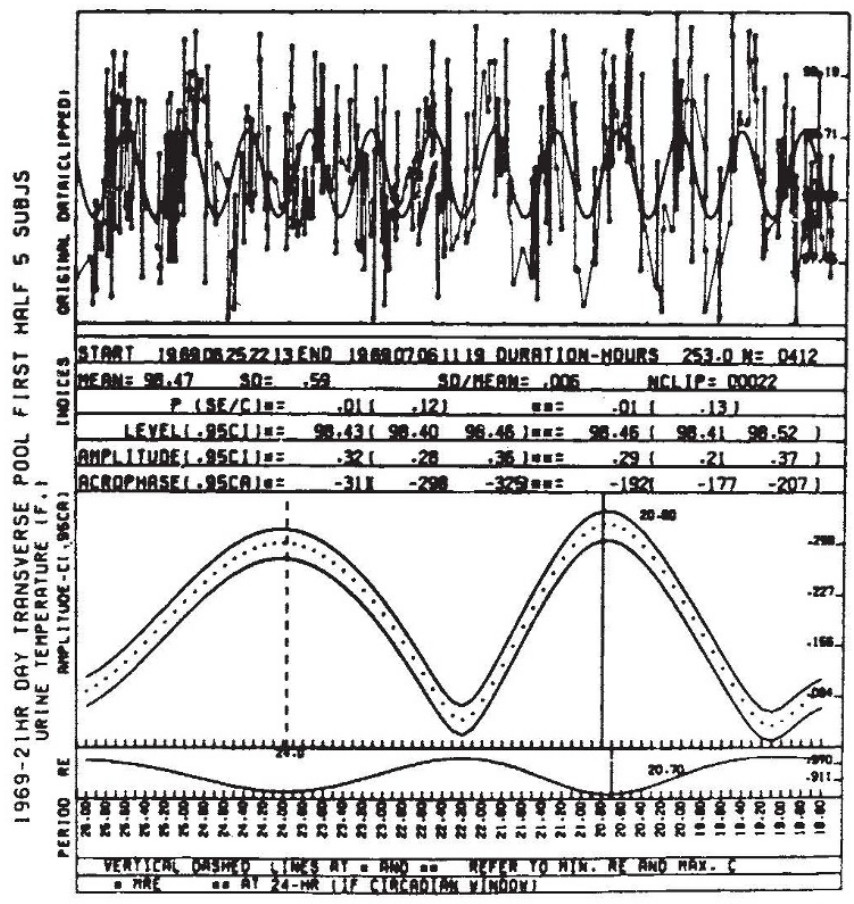

Fig. 2 Same study as Fig. 1. Urine temperature data of remaining subjects ( 3 adults, $2 \hat{\alpha}+1$ 을 and 2 boys aged 8 and 9) for first 1 s weeks of 3 week $21 \mathrm{~h}$ "day" study. There are two best fit frequencies in the circadian spectrum-one of the presumed endogenous component (about $24 \mathrm{~h}$ ) and the other at the environmental frequency.
With others, I have made extensive studies of the effect of a $21 \mathrm{~h}$ "day" (8 "days" per calendar week) on human circadian rhythms. One object of such studies is to separate circadian rhythms into environment and/or endogenous components. In these circumstances human body temperature rhythm may show only an about $24 \mathrm{~h}$ component in a computer analysis in which cosine waves at different circadian frequencies are fitted by least squares (Fig. 1). Other subjects for this variable show a mixture of endogenous (about $24 \mathrm{~h}$ ) and environmental components (Fig. 2) (first 1.5 weeks of 3 week study); moreover, this amplitude ratio (about $24.0 \mathrm{~h} / 21.0 \mathrm{~h}$ ) did not change appreciably in the second 1.5 weeks of the study (Fig. 3).

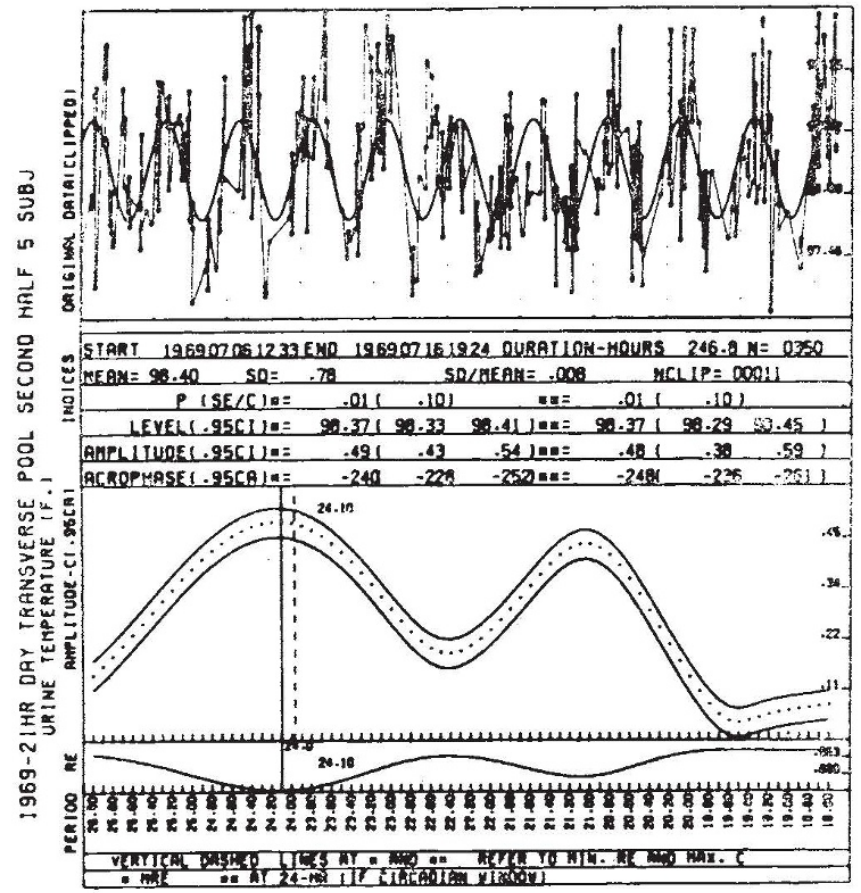

Fig. 3 Same study and subjects as Fig. 2. Second $1 \frac{1}{2}$ weeks of 3 week $21 \mathrm{~h}$ study. Two frequencies emerge as in Fig. 2 and the greater amplitude is the endogenous component. This is the opposite of what one would expect if it required an input from the routine to sustain it.

In other words, the endogenous biological mechanism for this rhythm (and for review of others see ref. 2) does not necessarily need to be sustained by food and sleep.

H. W. Simpson

University Department of Pathology,

Royal Infirmary, Glasgow C4

Received January 18, 1971.

1 Young, M., and Ziman, J., Nature, 229, 91 (1971).

2 Simpson, H. W., Halberg, F., and Lobban, Mary, Arctic Anthropology, 7, 144 (1970).

\section{Is the Haptic Müller-Lyer a Visual Phenomenon?}

Grometric illusions of active touch, or haptic illusions, resemble their visual counterparts ${ }^{1-3}$, which suggests that a single process underlies both phenomena. Over ${ }^{4}$ has argued from this that a purely visual theory such as Gregory's ${ }^{5}$ is untenable because the interpretation of visual illusions in terms of depth cues is clearly inapplicable for haptic/tactile space. Gregory (vide Horrell ${ }^{6}$ ) has replied by suggesting that in a haptic illusion there is some form of cross-modal transfer (possibly involving visual imagery) such that the haptic information is dealt with centrally just as if it were visual in 